\title{
FABRICATION OF SEMI-AUTOMATIC AGRO PADDY HARVESTING MACHINE
}

\author{
A K Murthy \\ Professor, Department of M.E, AMC Engineering College, Bangalore, India. \\ Prabhu Kumar Sharma R, Monish N S, Pavan S, Shankaranag B \\ Student, Department of M.E, AMC Engineering College, Bangalore, India.
}

\begin{abstract}
Recently there has been shortage of skilled labour available for agriculture purpose. Because of this shortage the farmers have transitioned to using harvesters. Cutting crops manually using labour is very time lengthy \& time-consuming task. The harvesters are available for purchase, but because of their high costs, they are not affordable. However agricultural groups make these harvesters available for rent on hourly basis, but the small holding farm owners generally do not require the full featured combined harvesters. Hence there is a need for smaller \& efficient combined harvesters, which would be more accessible and also considerably cheaper. The mission is to create a portable user friendly and low cost mini paddy harvesting machine. The idea is to create a machine which is cheap and will reduce the labour required to harvest crops
\end{abstract}

Key words: Fabrication, Agro Paddy, Harvesting Machine.

Cite this Article: A K Murthy, Prabhu Kumar Sharma R, Monish N S, Pavan S, Shankaranag B, Fabrication of Semi-Automatic Agro Paddy Harvesting Machine, International Journal of Advanced Research in Engineering and Technology, 10 (3), 2019, pp 140-147.

http://iaeme.com/Home/issue/IJARET?Volume=10\&Issue=3

\section{INTRODUCTION}

Recently there has been shortage of skilled labour available for agriculture purpose. Because of this shortage the farmers have transitioned to using harvesters. Cutting crops manually using labour is very time lengthy \& time consuming task. The harvesters are available for purchase, but because of their high costs, they are not affordable. However agricultural groups make these harvesters available for rent on hourly basis, but the small holding farm owners generally do not require the full featured combined harvesters. Hence there is a need for smaller \& efficient combined harvesters, which would be more accessible and also considerably cheaper. The mission is to create a portable user friendly and low cost mini paddy harvesting machine. The idea is to create a machine which is cheap and will reduce the labour required to harvest crops.

Harvesting of crops is one of the most labour intensive operation, which is to be carried out at an appropriate stage of crop maturity to minimize the field losses, thereby, to increase the crop yield. 
Field crop harvesting operation includes holding, cutting and windrowing of crop. It is important to apply good harvesting methods to: -

\section{Maximize grain yield.}

2.Minimize grain damage \& quality deterioration.

Generally, traditional methods of harvesting crops manually is by using sickles and knives, it is highly time consuming and labour intensive drudgery some act. To minimize the time and labour involved, various power tiller operated/ tractor operated / self-propelled harvesters/ harvesters and combined harvesters are available. Each type of harvester has its own merits and demerits; common demerit among these mechanical harvesters is their high initial cost.

This machine targets the small scale farmers who have land area of less than 2 acres. This machine is compact and can cut up to three rows of paddy plant. It has a chain saw which cuts the crop in rotary motion, which runs on a 2-stroke petrol engine. A collecting mechanism is provided for the collection of crops to one side after cutting. This mechanism is powered by a car wiper motor. This compact harvester is manufactured using locally available spare parts and thus, it is easily maintainable. This harvester might be the solution to the problems faced by a small scale farmer regarding cost and labour implementation.

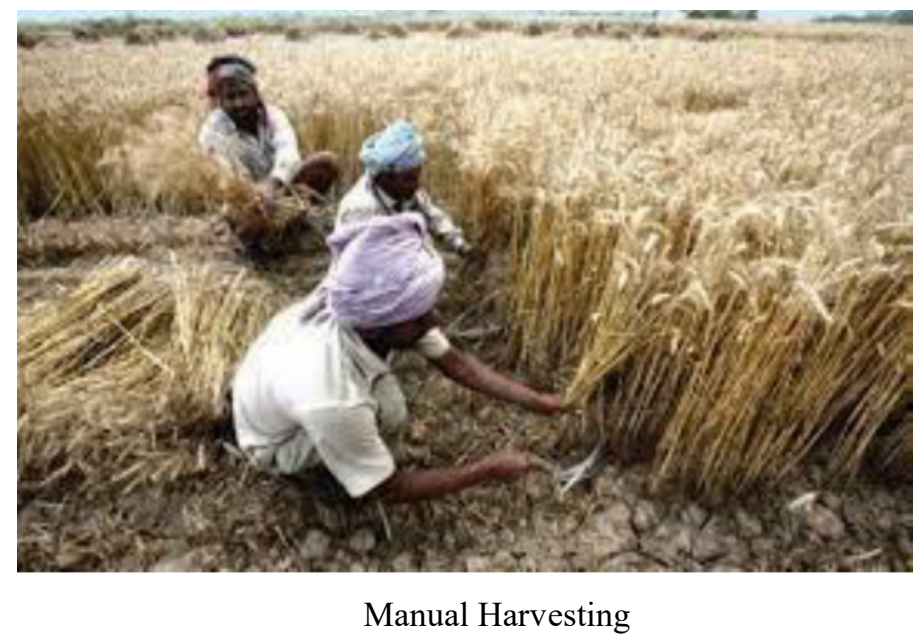

Farming is most widely followed profession in India. Agricultural products contribute a major portion to our economy. Engineering science has brought tremendous changes in traditional methods of agriculture viz. sowing, planting, irrigation, fertilizer spraying, harvesting, etc. However to increase our economic condition, we must increase the productivity and quality of our farming activities. Nowadays very few skilled labours are available for agriculture. Because of this shortage the farmers prefer to use harvester harvesters.

These harvesters are costly and only available of very large-scale farming. However, agriculture groups make these available for rent on an hourly basis. But the small holding farm owners generally do not require the full featured combine harvesters. Also, these combine harvesters are not available in all parts of rural India due to financial or transportation reasons. Thus, there is a need for a smaller and efficient combine harvester which would be more accessible and also considerably cheaper. The mission is to create a portable, user-friendly and low cost mini harvester taking into account the requirements of current situation; the idea was created to prepare a machine which is cheap and will reduce the labor required to cut crops. This machine has the capability and the economic value for fulfilling the needs of farmers having small land holdings. This machine is cost effective and easy to maintain and repair for the farmers. The machine model is designed based on the demand for a compact and economical harvester. This demand is taken into consideration by consulting farmers in person, for their problems and requirements. Taking into account the present scenario of corn harvesting we 
decided to prepare a model of corn harvester with compact construction which will be mostly suitable for farmers having small and for agriculture. The machine prototype will be economical and most convenient for cutting corn stalks and other similar plants having same or less shear strength than corn. Harvesting is the process of gathering a ripe crop from the fields. Harvesting is the cutting of grain or pulse for harvest, typically using a scythe, sickle, or harvester. Process automation has increased the efficiency of both the seeding and harvesting process.

\section{PROBLEM STATEMENT}

- Manual labor takes time and is not effective as they can work for 3-4 hours at a stretch.

- Even if the land holding is small, it takes two or three days to completely harvest the crop.

- High costs of machines and maintenance, no availability of appropriate agricultural machines and equipment that cater to and suit the requirements of small scale farms.

\section{OBJECTIVE}

- To formulate an idea to suit our required functionality that is to harvester the crops.

- To develop the idea to suitable mechanical principles and to design the idea to practice.

- To fabricate the design with the knowledge and the selected material which are cost effective.

\section{PRESENT METHOD}

Hand harvesting is done by various means, including plucking the ears of grains directly by hand, cutting the grain stalks with a sickle, cutting them with a scythe, or a scythe fitted with a grain cradle. Harvesting is usually distinguished from mowing, which uses similar implements, but is the traditional term for cutting grass for hay, rather than harvesting cereals.

\section{MANUAL CROP CUTTING}

The stiffer, dryer straw of the cereal plants and the greener grasses for hay usually demand different blades on the machines. The harvested grain stalks are gathered into sheaves (bunches), tied with string or with a twist of straw. Several sheaves are then leant against each other with the ears off the ground to dry out, forming a stood. After drying, the sheaves are gathered from the field and stacked, being placed with the ears inwards, then covered with thatch or a tarpaulin; this is called a stack or rick. In the British Isles a rick of sheaves is traditionally called a corn rick, to distinguish it from a hay rick ("corn" in British English retains its older sense of "grain" generally, not "maize"). Ricks are made in an area inaccessible to livestock, called a rick-yard or stack-yard. The corn-rick is later broken down and the sheaves threshed to separate the grain from the straw.

\section{CROP CUTTING USING MACHINE}

To the cutting and threshing machine for seed separation this method the crop are remove as mentioned in the traditional method. These method crops are tied together to from a bundle. These bundles are garnered and taken to threshing machine. This machine separates the seed from the crops.

\section{COMBINE CROP CUTTING MACHINE}

The combination of crop cutting machine is to combine the three operations like as cutting, harvesting and winnowing into a single process. The combination of crop cutting machine is the most economically labor saving. 


\section{METHODS AND EQUIPMENT FOR HARVESTING MAJOR CROPS}

Harvesting of crops like paddy and soybean has to be done carefully as the matured grains easily detach from the ear heads/pods and, therefore, cannot be harvested by fast working tools or machines. Bengal gram, green gram, lentils are to be harvested at ground level. Oilseed crops pose different type of problems to engineers for mechanization of their harvesting. Safflower is a spiny crop and difficult to harvest even manually. This also needs gentle handling. Farmers follow different methods for harvesting of rapeseed/mustard and pigeon pea. Mostly, farmers harvest these crops at branch level, but small farmers harvest these crops at ground level. Harvesting of root crops involves digging, shaking to remove adhering soil, windrowing or stacking and picking. A good root crop harvester should give maximum recovery and cause minimum damage to pods or tubers. The harvesting methods followed by farmers for major crops are as follows: Cereal crops Wheat and Rice: Harvesting of these crops is traditionally done by using local sickle. Improved serrated blade sickles are also in use.

The following machines are available for efficient harvesting of these crops:

i. Self-propelled walking type harvester ii. Harvester binders iii. Tractor front and rear mounted harvesters iv. Combine harvesters

\section{COMPONENTS}

\section{Main Frame}

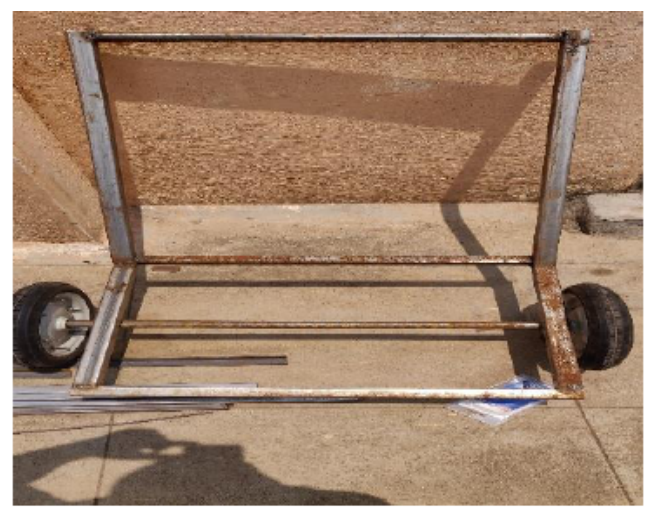

Main Frame

The main frame of the harvester is made of mild steel square hollow rod. This main frame is provided with wheels which prove for the easy motion of the harvester in fields, and it makes the harvester a portable one.

\section{Chainsaw}

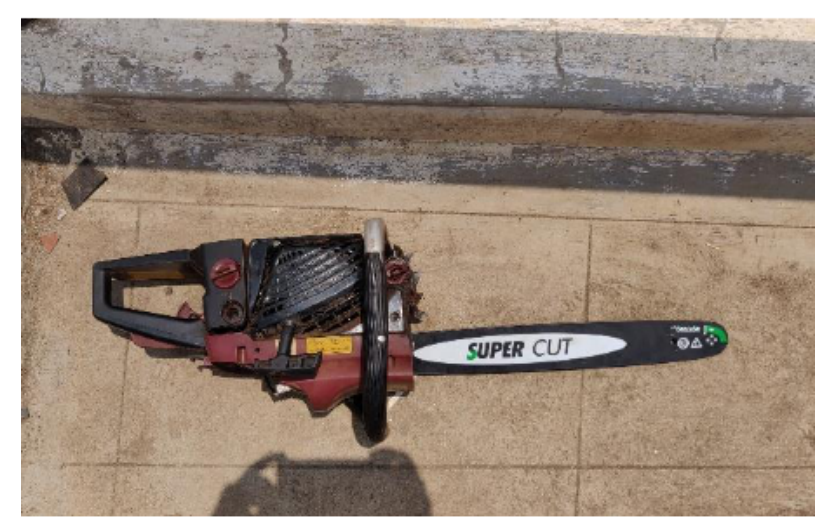

Chainsaw 
A chainsaw is a portable, mechanical saw which cuts with a set of teeth attached to a rotating chain that runs along a guide bar. It is used in activities such as tree felling, bucking, pruning, cutting firebreaks in wildland fire suppression and harvesting of firewood. Chainsaws with specially designed bar and chain combinations have been developed as tools for use in chainsaw and chainsaw mills. Specialized chainsaws are used for cutting concrete. Chainsaws are sometimes used for cutting ice, for example for ice sculpture and in Finland for winter swimming. Someone who uses a saw is a sawyer

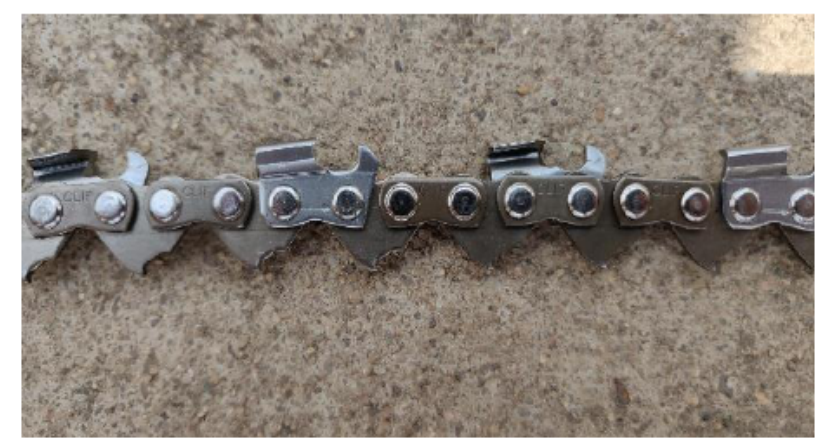

Cutting Chain

Usually each segment in this chain (which is constructed from riveted metal sections similar to a bicycle chain, but without rollers) features small sharp cutting teeth. Each tooth takes the form of a folded tab of chromium-plated steel with a sharp angular or curved corner and two bevelled cutting edges, one on the top plate and one on the side plate. Left-handed and righthanded teeth are alternated in the chain. Chains come in varying pitch and gauge; the pitch of a chain is defined as half of the length spanned by any three consecutive rivets (e.g., $8 \mathrm{~mm}$, 0.325 inch), while the gauge is the thickness of the drive link where it fits into the guide bar (e.g., $1.5 \mathrm{~mm}, 0.05 \mathrm{inch}$ ). Conventional "full complement" chain has one tooth for every two drive links. "Full skip" chain has one tooth for every three drive links. Built into each tooth is a depth gauge or "raker" which rides ahead of the tooth and limits the depth of cut, typically to around $0.5 \mathrm{~mm}(0.025 ")$. Depth gauges are critical to safe chain operation. If left too high they will cause very slow cutting, if filed too low the chain will become more prone to kick back. Low depth gauges will also cause the saw to vibrate excessively. Vibration is not only uncomfortable for the operator but is also detrimental to the saw.

\section{Wiper Motor}

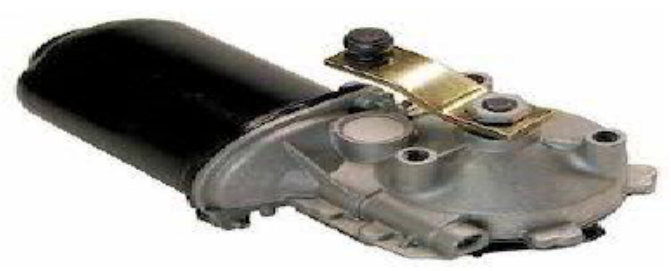

Wiper Motor

It is a 2-Speed $12 \mathrm{~V}$ DC motor, whose specifications are as follows

Rated torque: 53 in-lb.

Stall torque: 177 in-lb.

Unload high speed: 50rpm, 1.5A (12VDC)

Unload low speed: 35rpm, 1.0A (12VDC)

Maximum wattage: 50W/12VDC.

Motor noise: $<45 \mathrm{~dB}$. 
Spindle/Post thread size: M-6.

Spindle rotates 360 degrees.

It is used to power the conveyer belt which shall collect the crops to one side of the machine after cutting the crop.

\section{V 9AH Battery}

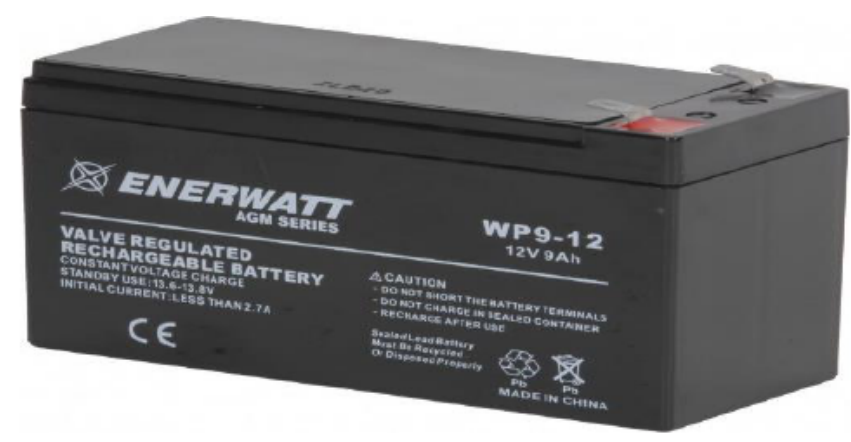

12 V 9AH Battery

A $12 \mathrm{~V}$ 9Ah rechargeable battery is used to power the car wiper motor, The motor which is used to run the conveyer chain.

\section{Solar Panel}

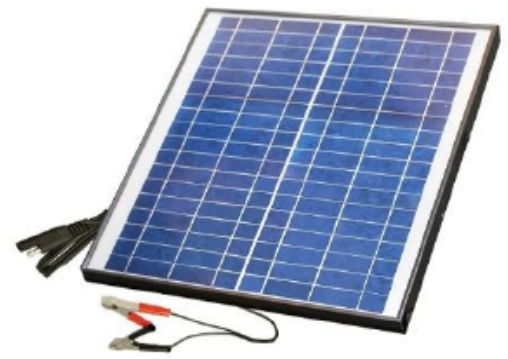

Solar Panel

A 22W Solar panel is used to recharge the battery, in case of power loss.

\section{Conveyer Chain}

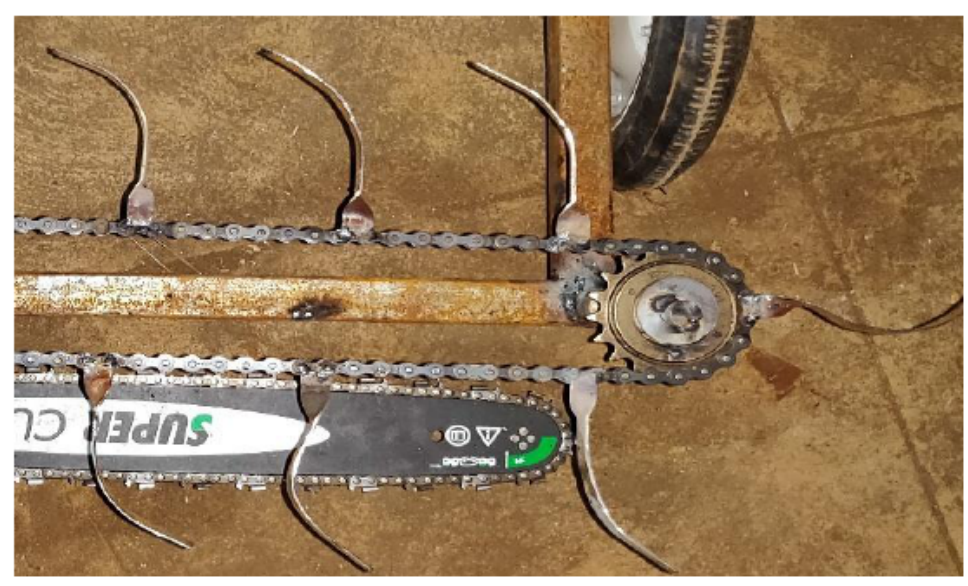

Conveyer Chain 
As shown in the above image, a conveyer chain is a modified bicycle chain, onto which hook like structures are mounted. This chain is driven by the wiper motor, by means of a pair of bicycle freewheels.

\section{FINAL ASSEMBLY OF THE MACHINE}

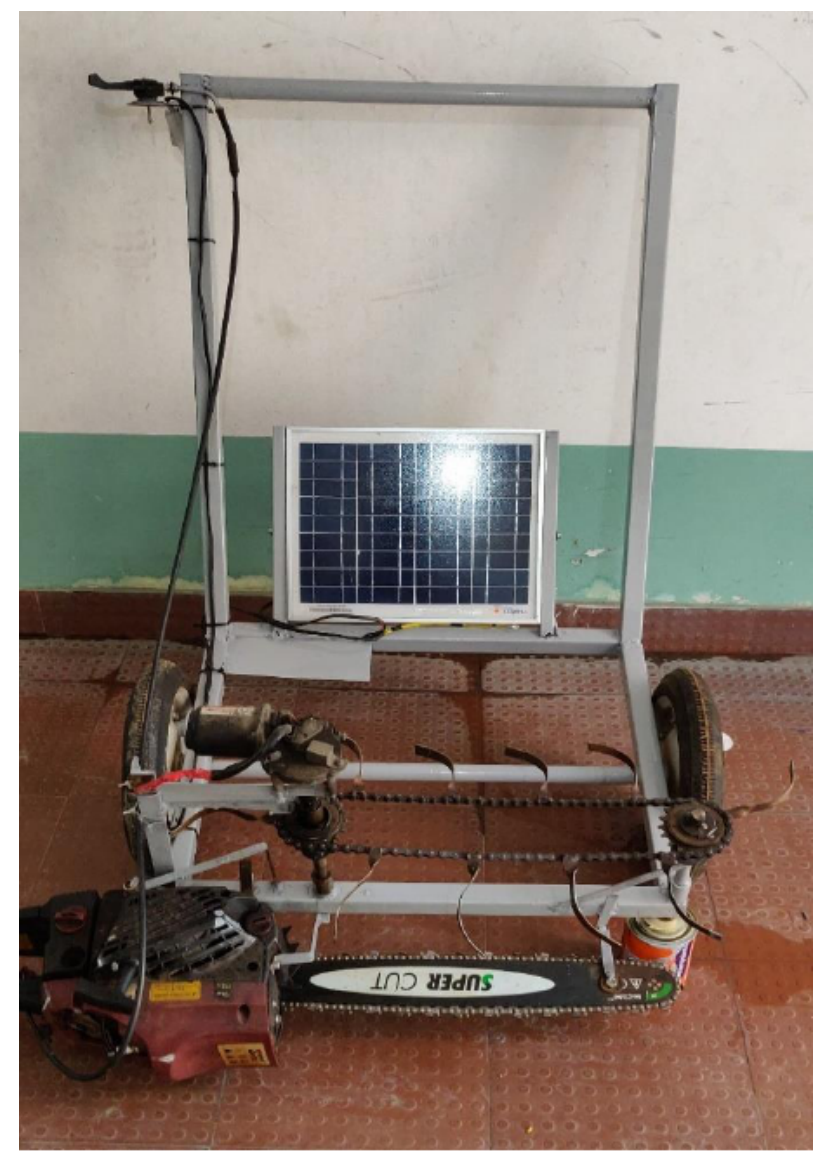

The above image shows the final machine after assembly.

The harvesting machine consists of a main frame on to which the various parts are mounted. The chain saw is mounted on the front part of the machine to cut the crops (paddy),and the accelerator is provided on the handle to control speed, and exactly parallel to the chainsaw the conveyer chain is fixed to convey the cut crops to one side of the machine. A wiper motor is provided to run the conveyer chain, this motor is powered by a $12 \mathrm{~V} 9 \mathrm{AH}$ battery, which is a rechargeable battery. The battery can be recharged either by an external energy source or solar energy. To charge the battery by solar energy, a $22 \mathrm{~W}$ solar panel is mounted with the machine. The harvesting machine after the final assembly is as shown in the figure.

\section{WORKING OF THE MACHINE}

The machine is started by starting the engine of the chainsaw by pulling the cable of the starter of the chain saw, once the engine is started, the conveyer is switched on by the switch provided at the handle. The harvester is then pushed forward into the crop (paddy) field, once the cutting chain of the chainsaw comes in contact with the crop it chops the crop and the crop is pulled away from the machine by the means of conveyer chain. The speed of the engine can be controlled as per the requirements by the accelerator at the handle.

Once the harvesting of the crops is completed, the engine is turned off by a switch provided and the motor is switched off. 


\section{ADVANTAGES OF HARVESTING BY MACHINE}

- Additional grain obtained: Mechanized harvesting eliminates grain loss during manual cutting of the crop, tying the crop for carrying, transporting the harvest and from incomplete threshing. A 5\% to 10\% increased yield has been demonstrated.

- Time savings in the field: Our combine harvester can harvest and thresh one acre of land in one hour. The manual method would require 12 people, one full day to perform the same task, excluding threshing.

- Reduced time to market: The manual method requires a separate step for threshing, which adds multiple days, and another day or two for cleaning. Thus the time from crop cutting to market ready is a week or more for the manual method as compared to an hour or so per acre for the combine harvester process.

- Cleaner grain: the mechanized harvesting produces cleaner grain as compared to the manual process, for which the market often is willing to pay a premium.

- Reduced net cost: the mechanized harvesting can be priced to be lower than the cost of manual harvesting.

\section{REFERENCES}

[1] Design and Development of manually Operated Reaper, P.B.Chavan, D .K. Patil, D .S. Dhondge, IOSR Journal of Mechanical and Civil Engineering (IOSRJMCE) e-ISSN: 22781684,p-ISSN: 2320-334X, Volume 12, Issue 3 Ver. I (May. - Jun. 2015), Pp: 152

[2] Deepa M U, Bindu Prakash, Achu G Kumar, Arjun Anil, Aromal B Raj, Krishna Sabu and Nithila S Kurup, Dc Home Using Battery -Less PV Harvesting System with RTC Based Solar Tracking, International Journal of Electrical Engineering and Technology (IJEET), Volume 6, Issue 4, April (2015), pp. 01-08

[3] Design and analysis of crop cutter, R. A. Ghumadwar, MR. V. H. Bankar, International journal of pure and applied research in engineering and technology, ISSN: 2319-507X, 2016; Volume 4 (9): $242-246$

[4] A Review: Design and Analysis of Arm of Reaper and Binder Machine, Tejaskumar Patel, Chetan Vora and Vipulkumar Rokad, International Journal for Scientific Research \& Development, Vol. 4, Issue 1, 2016

[5] Mohammad M J, Sai Charan G, Ravindranath R, Reddy YV and Altaf SK, Design, Construction and Evaluation of Rain Water Harvesting System for SBIT Engineering College, Khammam, Telangana. International Journal of Civil Engineering and Technology, 8(2), 2017, pp. 274-281.

[6] Design and fabrication of crop reaper, Shalini P. Shivankar, Ashish. M. Wankhade, Mansur. N. Syed, International journal for engineering applications and Technology, ISSN: 2321-8134

[7] Design and performance analysis of handy harvester, P. Chakaravarthi, Abuthaker. A, Arun. S, Karthikeyan. U, Vol-2 Issue-2 2016 IJARIIE-ISSN (O)-2395-4396 